IZA DP No. 9655

Consumption Smoothing in the Demand for Health Care

Nicolai Kristensen

Henrik Lindegaard Andersen

January 2016 


\title{
Consumption Smoothing in the Demand for Health Care
}

\author{
Nicolai Kristensen \\ Danish Institute for Local and Regional Government Research (KORA) \\ and IZA \\ Henrik Lindegaard Andersen \\ Danish Institute for Local and Regional Government Research (KORA)
}

\author{
Discussion Paper No. 9655 \\ January 2016
}

IZA

P.O. Box 7240

53072 Bonn

Germany

Phone: +49-228-3894-0

Fax: +49-228-3894-180

E-mail: iza@iza.org

\begin{abstract}
Any opinions expressed here are those of the author(s) and not those of IZA. Research published in this series may include views on policy, but the institute itself takes no institutional policy positions. The IZA research network is committed to the IZA Guiding Principles of Research Integrity.

The Institute for the Study of Labor (IZA) in Bonn is a local and virtual international research center and a place of communication between science, politics and business. IZA is an independent nonprofit organization supported by Deutsche Post Foundation. The center is associated with the University of Bonn and offers a stimulating research environment through its international network, workshops and conferences, data service, project support, research visits and doctoral program. IZA engages in (i) original and internationally competitive research in all fields of labor economics, (ii) development of policy concepts, and (iii) dissemination of research results and concepts to the interested public.
\end{abstract}

IZA Discussion Papers often represent preliminary work and are circulated to encourage discussion. Citation of such a paper should account for its provisional character. A revised version may be available directly from the author. 


\section{ABSTRACT}

\section{Consumption Smoothing in the Demand for Health Care*}

We investigate how, in temporary economic hardship, agents change their consumption of health services, and how this depends on whether the service is universally free-of-charge visits to GP's or privately co-financed dental care. We find that own expenditures for dental care decrease. The decrease is mainly seen in preventive treatment, a durable good, but for the lowest income quartile there is also a substantial decrease in expenditures for curative dental care, although this is a consumption good with very low intertemporal substitution. The expenditures for GPs are unaltered. The findings indicate that consumption of health services critically depends on the existence of user charges versus universal coverage. The welfare loss associated with postponement of preventive care is considerably lower than the welfare loss related to a decrease in the use of curative dental care induced by economic hardship. The policy implication could be public support for means-tested curative dental services.

JEL Classification: D1, D6, H23

Keywords: health care systems, consumption smoothing, social gradient

Corresponding author:

Nicolai Kristensen

Danish Institute for Local and Regional Government Research (KORA)

Købmagergade 22

1150 Copenhagen $\mathrm{K}$

Denmark

E-mail: nikr@kora.dk

\footnotetext{
* We thank Paul Bingley, Eskil Heinesen, Astrid Kiil and Jan Rose Skaksen for helpful comments. We thank Camilla Dürke Tybing for computational assistance on an earlier version of the paper. Financial support from Helsefonden and KORA is gratefully acknowledged.
} 


\section{Introduction}

What happens to consumption of health services during temporary economic hardship?

Economic theory, as well as a large body of empirical work, has a lot to say about this question. Consumption theory predicts that temporarily strained circumstances, e.g. following an unemployment spell, may induce households to cut back on expenditures even though UI benefits serve to smooth consumption (Gruber 1997, Browning and Crossley 2000). In order to diminish the drop in household welfare induced by a temporary difficult financial situation - such as an unemployment spell - households may concentrate their expenditure cut back on durables (Browning and Crossley 2009). Following Grossmans seminal 1972 paper, health can be considered a durable good, and we may therefore expect to see a decrease in the use of health services in response to a spell of unemployment. ${ }^{1}$ If some health services are universally covered (by private or public insurance) while others are not, the theoretical prediction of a drop in consumption of health service would relate to services with user charges only.

A large body of literature has demonstrated the existence of a social gradient in health whereby people with higher socio-economic status (SES) have better health. This strand of literature has also established a causal impact from income to health, see e.g. Cutler and Lleras-Muney (2007), which in turn implies that a drop in income detoriates health. In isolation, this may induce an increase in the demand for health services following an unemployment spell. ${ }^{2}$

Grossman (1972) emphasizes the importance of time-costs related to investments in health. If the income shock arises due to an unemployment spell, the agent experiences a drop in the cost of time, which increases consumption of health services. Unemployment has also been shown to have a direct negative effect on health (Eliason and Storrie 2006, 2009b, 2010) and mortality (Eliason and Storrie 2009a, Browning and Heinesen 2012), although some studies fail to find this direct causal link (e.g. Eliason and Storrie 2010 for men). An unemployment shock may therefore be expected to increase the consumption of health care, because health (possibly) detoriates

\footnotetext{
${ }^{1}$ Some scholars argue that health should not only be seen as an investment but also as a consumption good (Mushkin 1962: 131). Grossman (1972) acknowledges this possibility.

${ }^{2}$ Note however, that while the correlation between SES and health is strong the causal link is weak. For instance, Clark \& Royer (2013) suggest caution as to the likely health returns to educational interventions focused on increasing educational attainment among those at risk of dropping out of high school.
} 
and because time-costs decrease.

In sum, the answer to the opening question is that in response to temporary economic hardship one should expect the consumption of health services to increase if there is universal coverage and no user charges, while in the case of user charges on health services any change in the consumption of health services depends on which factor dominate, and a priori health usage can either increase, stay constant or decrease.

In this paper, we test whether individuals' usage of health services responds to job loss, and how any response fits with economic theory. The motivation for the analysis is that it provides a simple setting for analyzing the importance of user charges for health services, which in turn has very large implications for public finances and private welfare.

The Danish context is of particular interest, since GP visits are universally free of charge, while dental health care, albeit subsidized, involves relatively high user charges. In order to avoid endogeneity problems regarding job loss, we construct a data set of plant closures in Denmark, following e.g. Eliason and Storrie (2009a) and Browning and Heinesen (2012). The analytical design here has the advantage that we can observe how the same individual shock affects both health services that are free of charge and health services with user charges. This provides an ideal setting in which the importance of payments to health services can be analyzed while holding both the exogenous shock as well as personal traits constant. To our knowledge, this has never been done before. The 1974 Rand Health Insurance Experiment (HIE) provides results relevant to our study, e.g. Manning et al. $(1985,1987)$. These studies were based on an large-scale experiment, in which families were assigned to one of 14 different fee-for-service plans or to a prepaid group practice. The random assignment makes a strong case for causal effects, and for this reason several studies based on these data still stand as a landmarks. Despite differences in outcome variables and study design, our findings are comparable and in line with Manning et al. (1985, 1987) in that we find that preventive dental care decreases overall and for all income subgroups while expenditures on GPs are unaltered. However, we also find that the use of curative dental care generally is left unaffected except for individuals from households with income in the lowest quartile. Manning et al. (1985) do not find this difference between preventive and curative care although the difference is in line with theoretical expectations.

The paper is organized as follows. In section 2, we describe the theoretical predictions in further detail. Next, the empirical strategy and data are described followed by a section with results and a subsequent discussion and conclusion. 


\section{Theoretical Background}

I this section, we briefly revisit the theoretical linkage between job displacement and health mentioned in the introduction. Second, using predictions from consumption theory, we outline hypotheses which we subsequently test empirically.

\subsection{Job Displacement and Health}

Job displacement may affect health through different channels. On average, income will decrease (Hijzen et al. 2010) and this is found to have both direct and indirect effects on health (Ruhm 1991, Cutler and Lleras-Muney 2007). An income decrease may result in a worsening of health through stressrelated diseases. It may also have a more indirect social and psychological based effect, due to loss of self-esteem, locus of control, self-identification and meaning of life. The consequences may be long term (Clark et al. 2001) and leave the unemployed individual more vulnerable to the impact of otherwise unrelated life events (Kessler et al. 1987).

As mentioned, the type of illnesses affected here are expected to be stress-related diseases such as circulatory diseases and depression. While these may very well require expert medical assistance, the entrance into the health care system is through referral by own GP. In addition, GP's are gatekeepers even for access to private care. ${ }^{3}$ Hence, we may meaningsfully look for any health effects caused by job displacement by looking at the use of GPs. Dental health can also be stress related. We return to this issue in the Discussion Section.

\subsection{Health, Dental Health and Consumption}

In Grossman's 1972-model, the demand for health is modelled as a function of, among other things, initial health, direct expenditures on health care and the cost of time. The demand for medical-care services can be derived from the demand for health, so that all factors that influence demand for health also influence demand for health care (Coffey, 1983). Two features of health care that makes it different from other types of consumption goods is individuals unpredictable demand for health care and individuals lack of knowledge about the quality of health care, Arrow (1963). However, these features are not strongly present in dental health care as noted by Sintonen and Linnosmaa (2000). They argue that dental care seldomly is an

\footnotetext{
${ }^{3}$ Except for 3 percent in public health insurance group A.
} 
'emergency', and that untreated dental illnesses rarely have dramatic consequences on an individual's health. In comparison with cancer and similar potentially mortal diseases this is true. However, we may still consider curative dental care as a consumption good with a very low intertemporal substitution - while routine prophylaxis or diagnostic examination, on the other hand, has a very high intertemporal substitution. ${ }^{4}$

If a transitory drop in income affects total expenditures, it is expected to primarily affect purchase of luxuries (Hamermesh 1982) and goods with high intertemporal substitution (Parker 1999), which under certain regularity conditions amount to the same thing, Browning and Crossley (2000). In this paper, a similar distinction in demand for medical care arises between preventive and curative (non-preventive) dental care. ${ }^{5}$ We expect a transitory income effect to have less impact (possibly none) on curative dental care, while preventive care, such as periodical check-ups, may be postponed in response to a transitory income shock (this distinction alludes to the notion that health should be seen not only as an investment but also as a consumption good, Mushkin 1962). The use of health services, including visits to dentists or GPs, are nevertheless (partly) to be seen as investments. These health investments are irreversible, as they can be considered durable commodities with no second hand market. According to Browning and Crossley (2009), and in line with Hamermesh (1982) and Parker (1999), we may expect to see not only a drop in the use of preventive dental care but also a drop in the demand for curative dental care for households that experience a severe transitory shock to their income. For drops in household income earnings less than about $20 \%$, the effect on non-durables is neglible (Browning \& Crossley, 2009).

Based on these considerations, we can outline the following theoretical predictions. Theory predicts that:

1. Expenditures on GP do not decrease and likely increase

2. Private dentist expenditures can either increase or decrease, but any increase will be lower than the expected increase in GP expenditures

\footnotetext{
${ }^{4}$ Another difference between dental health and health is in the production of dental health. Following a displacement, individuals may have more time to brush their teeth and in this manner substitute away from visits to the dentist.

${ }^{5}$ Available data contain information about type of care provided by dentists but not by GPs. This enables us to create a rough dichotomy between "preventive" and "curative", described further in Section 4. Coffey (1983) makes a similar distinction in the demand for physician visits.
} 
3. A decrease in private dental service expenditures will be more pronounced for preventive treatment vis-à-vis curative treatment

4. Reductions in dentist expenditures is larger for low income households, i.e. there is a social gradient

5. Any decrease in the demand for curative dental services will only occur for decreases in income of $20 \%$ or more

\section{Identification and Empirical Strategy}

We are interested in the causal relationship between job displacement and the consumption of health service, and how this differs between universally covered GP visits and visits to dentists, where user charges are levied. In order to identify a true causal relationship, it is important to analyze changes in employment status that are exogenous to the agent. Without exogeneity it would be unclear whether, say, something happened to the individual that caused him or her to become unemployed and at the same time detoriated health, and the employment status would then errounously be considered as the causal link.

To isolate the causal effect, we make use of plant closures, which arguably are exogenous to each individual worker's observable as well as unobservable characteristics, especially if the work place is large enough in terms of number of employees. A similar approach has frequently been adopted in the past, see Morris and Cook (1991) for an early survey. More recent papers include Eliason and Storrie (2009a), and Browning and Heinesen (2012). Unemployment spells following a plant closure avoid the selection problem whereby the least fit are made redundant, since plant closures, or massive lay-offs, can be considered exogenous to the individuals characteristics and personality.

We subsequently face a choice between adopting a difference-in-difference (DiD) estimation approach or matching. In both cases we would make use of differences within the treatment group of displaced workers use of health services over time compared to the differences within the control group of nondisplaced workers over time. Yet, the two approaches rely on fundamentally different identifying assumptions, Imbens \& Wooldridge (2009: 70). Either we rely on a common trend assumption (DiD) or assume unconfoundedness given lagged outcomes and other covariates. The key identifying assumption in DiD estimation is that any trend to health care expenditures would be the same among displaced and non-displaced in the absence of displace- 
ment (treatment). This common trend assumption might be violated if, say, employees in declining industries react to increased uncertainty by postponing visits to the dentist (even before they experience displacement) while employees in non-declining industries may feel more secure and not change their health investments.

With the rich data available here, we find it credible to rely on unconfoundedness. For instance, we include three year lags of the use of dentist or GP for each individual. This will pick up a lot of the otherwise unobserved idiosyncratic behaviour, much like individual fixed effects but possibly better since changes in health over the last years also will be captured. ${ }^{6}$ The year may be of importance here due to the global financial crisis starting around 2008. To ascertain proper matching we therefore make exact matching on calendar year.

As a further measure to provide reliable and robust results, we combine matching with linear regression analysis. This approach, first developed by Rotnitzky \& Robins (1995), is increasingly being advocated in applied work, see e.g. Hirano \& Imbens (2001) and Ho et al. (2007). The latter study points out that, except in the extraordinary case where matching is exact, simple parametric regression will ameliorate the parameter estimates compared to a simple difference in means without controls for potential confounding variables. ${ }^{7}$ This double-robust estimator requires a model for estimating the propensity score and a model for estimating the outcome in the same estimator. The advantage of this approach is unbiased estimates of the treatment effect, when either one or both of these models are correctly specified. The unconfoundedness assumption is still necessary, but as Hirano \& Imbens (2001) demonstrate, the results become more robust to any remaining misspecification.

We estimate the average treatment effect on the treated (ATT), that is

$$
\alpha=E[Y(1)-Y(0) \mid D=1]=E[Y(1) \mid D=1]-E[Y(0) \mid D=1]
$$

\footnotetext{
${ }^{6}$ Imbens \& Wooldridge (2009: 70) make the same recommendation: "As a practical matter, the DID approach appears less attractive than the unconfoundedness-based approach in the context of panel data. It is difficult to see how making treated and control units comparable on lagged outcomes will make the causal interpretation of their difference less credible, as suggested by the DID approach". Chabé-Ferret (2015) presents arguments in more favor of DID under certain circumstances.

${ }^{7}$ With matching not being exact, using the difference in means estimator is equivalent to assuming that any remaining imbalance in the matched sample is strictly unrelated to the treatment. Often this will not be the case.
} 
where $Y(0)$ and $Y(1)$ denote use of health services, 0 denotes non-displacement, 1 denotes displacement, and $D$ is an indicator for displacement status.

The last term on the right hand side is the unobserved counterfactual, which is estimated using propensity score matching and robust standard errors. ${ }^{8}$ Instead of using the normal weighting estimator we use an additional regression adjustment to correct for possible remaining covariate bias between treatment and control groups. This leads to the following regression model

$$
Y_{i}=\beta_{0}+\alpha D_{i}+\beta_{1} X_{i}+\beta_{2}\left(X_{i}-\bar{X}_{1}\right) D_{i}+\varepsilon_{i}
$$

where $\bar{X}_{1}$ is the sample average of $X$ for the subsample of treated units, and $\alpha$ is the ATT parameter. ${ }^{9}$ The double-robustness enters here by the addition of $X_{i}$. If $Y$ is regressed solely on $D$ and the constant $\beta_{0}$ the estimate is equivalent to the more standard propensity score matching estimator.

\section{Data}

The analysis is based on administrative records maintained by Statistics Denmark. All persons in Denmark have a 10-digit central personal registration (CPR) number. With this number, Statistics Denmark is able to track individuals over time and across many different administrative registries. All workplaces are also registered, and it is possible to identify workers in each workplace. We use data for the years 2005-2009 on individuals demographic and labor market characteristics including their education, tenure and familiy characteristics. These individual-level data are merged with annual workplace information. To this rather standard set of variables we add information on consumption of health services over the years 2002-2011.

\subsection{Health Data}

Three sources of health data are applied. Firstly, all publicly subsidized visits to dentists are recorded in The National Health Insurance Service Registry. This contains information on dental services included in the collective agreement, which covers approximately 55 percent of all dental care

\footnotetext{
${ }^{8}$ The double robust estimator used here is described in Emsley et al. (2008).

${ }^{9}$ As we estimate the ATT, the weights applied for the ATT parameters are 1 for the treated group and $\frac{\widehat{e_{i}}(x)}{1-\widehat{e}_{i}(x)}$ for the control group, where $\widehat{e}_{i}$ is the estimated value of the propensity score function for control group observation $i$.
} 
expenditures in Denmark. ${ }^{10}$ Following Grossman and Rand (1974), the services reported in this registry can be split into preventive and curative (or remedial) services:

\begin{tabular}{ll}
\hline \hline Preventive $^{11}$ & Curative \\
\hline Dignostics & Root treatment \\
Regular examination & Extraction of tooth \\
X-ray, bitewings & Operative removal of tooth, root of tooth, and cyst \\
Teeth cleaning & Periodontal treatment \\
\hline \hline
\end{tabular}

Clearly, this dichotomy is not well defined in the sense that X-ray, for instance, will often be a service required in combination with one or more of the curative services.

In each of the above groups, a number of different services are included. Prices for the services are fixed in the collective agreement between the Regions (the public sector) and the Association of Dentists, and these prices have been added to the data set. Exceptions to this rule exist for about 10 types of services where the public subsidy is fixed, but user charges may vary across dentists. ${ }^{12}$ These so-called free services often vary in terms of severity, and hence prices will vary accordingly. The registry includes dates on which the dentist charges the Region; sometimes the same day as the service, but usually up to a month later. Dental services are connected to the CPR number, and it is therefore possible to trace individuals over time and link this information to other registries. ${ }^{13}$

Secondly, all visits to general practitioner (GP) are also recorded in The National Health Insurance Service Registry. GP visits are universally covered in Denmark and hence free of charge. However, a price is agreed on by the association of GPs and the Regions, and we are therefore able to observe the cost of each GP visit as well as the date on which the GP makes his or her claim on the public for services provided (as with dentists, this is usually done in weekly or monthly bulks).

\footnotetext{
${ }^{10}$ The 55 percent is an estimate based on a survey, prepared by A Data for the association of dentists, among 70 clinics in 2006. The exact number is unknown. Absent from our data is information about procedures such as dental implants, dental crones and so forth.

${ }^{11}$ By 'preventive' we mean 'primary prevention', i.e. prevention that consists of actions that reduce the occurence or incidence of disease, Kenkel (2000).

${ }^{12}$ For the free services, an average was calculated across 10 dentists in each of the 5 regions. See https://www.sundhed.dk/. The free services constitute approximately 10 percent of the services included in The National Health Insurance Service Registry.

${ }^{13}$ Fillings are not included in the analysis, due to a data break in 2007-2008.
} 
Thirdly, it is possible to obtain additional subsidies for dental treatments through membership of the private health insurance company called "danmark", which is a non-profit company. Membership of danmark is unobserved in the registers. However, such information is available in large scale survey data called SUSY. ${ }^{14}$ Using SUSY, we make an auxiliary regression whereby we calculate the probability of membership of danmark and combine this probability with the subsidy attached to membership. There are different types of membership, but for our purposes the subsidies are almost constant across different types of membership. ${ }^{15}$

\subsection{Establishing Treatment and Control Groups}

In this section, we describe how our treatment and control groups are defined. The "treatment" here is being displaced, and the concern is to ensure that this shock is truly exogenous. To this end, we look at plant closures and follow the displaced employees from these plants, as described in Section 3. The approach and description here follow Browning and Heinesen (2012), although a few changes have been made vis-à-vis their choices and although they apply a very different method otherwise.

Plant closure The initial sample includes all private workplaces from 2004-2009. In order to ensure real displacements (and not just reorganization), the sample is limited to workplaces with a single plant only. The administrative data include codes on plant closure. We transform the calendar years to periods, with period 0 being the year of plant closure - and subsequently we stack data with different calendar years as the base year. However, plants that are closing down may often be in a process of closure lasting a number of years, and it is therefore not necessarily the very last year observed in the data that should be defined as period 0. Browning and Heinesen (2012) discuss this issue at length, and we follow their choice and define the year of plant closure as the year with the greatest absolute reduction in the number of employees.

Treatment and control groups The treatment group consist of workers displaced due to plant closure. For both our treatment and our control group we impose the restriction that they must be aged 20-60, have at least

\footnotetext{
${ }^{14}$ The National Health Interview Survey is a general health and morbidity survey carried out by the National Institute of Public Health. See http://www.si-folkesundhed.dk/susy/.

${ }^{15}$ We here follow Simonsen et al. (2015). We thank Niels Skipper for providing parameter estimates for the auxiliary regression.
} 
3 years of tenure, be full-time employees and have annual gross earnings of minimum 150,000 DKK in the year prior to plant closure. We also exclude self-employed persons and assistant spouses. With these limitations, we obtain a sample of workers with a strong labor market attachment.

A person can only be in the treatment group in one baseyear. If the requirements are met for more than one year, we select the first eligible year as the baseyear. The control group is furthermore restricted to employees at plants with downsizing of no more than $10 \%$ in the base year and the year after.

\subsection{A First Look at the Data}

Looking at the average level of people's own expenditures on dentists and public expenditures on GPs, we note that, based on cross sectional data for the year prior to plant closure, the levels of expenditures between treatment and control are very similar, see Table 1 . Also, note that the level of own expenditures on dentists, on average 482 (483) DKK for the control (treatment) group, are relatively close to the expenditures paid by the public sector for visits to GP (on average 572 and 583 DKK, for the control and treatment group, respectively). ${ }^{16}$

[Table 1 about here]

The standard deviations are large reflecting that a large proportion do not visit their GP or a dentist during a given calendar year. More than 25 percent of the sample have zero expenditures on dentists (in period 0), while the 25th percentile of expenditures on GP is at 100 DKK. The distributions of these expenditures are shown in Figure 1.

[Figure 1 about here]

The break down of own expenditures to dentist reveals that the own payment to preventive dentist treatment accounts for approximately 60 percent of the total own payments for dentists measured in the year prior to plant closure.

Among the background variables included in Table 2, we note that, in general, they have the same level across treatment and control groups, and that there are no significant differences between the groups. Still, there are

\footnotetext{
${ }^{16}$ In recent years, the exchange rate has fluctuated around 5.5 DKK for one USD. Hence, on average approximately 100 USD are spent on GPs and own cost for dentists, respectively.
} 
differences. For instance, some of the indicators for industry have very different values. The industry "manufacturing, metals and machinery" is 0.10 in the treatment group and 0.17 in the control group (standard deviations are relatively large so the difference is insignificant). This indicates that our identification procedure with plant closures needs to be supplemented with a re-weighting procedure (such as matching) in order to credibly identify a causal effect. On average, the group of displaced workers is slightly older than the control group, which indicates that more mature industries are closing down. The level of education is also slightly lower among the treated vis-à-vis the control group. This is not surprising either, as plant closures in Denmark primarily occur among the manual, labor intensive workplaces where increased international competition from low-wage countries is most prevalant.

[Table 2 about here]

How does plant closure spell out in the data? Figures 2-4 show that the treatment and control groups are indeed very close and show similar trends prior to plant closure, which occurs in period 0-1. The average individual gross income for the displaced workers decreases from year 0 to year 1 and further down in year 2, while for the non-displaced it flattens out a little (probably reflecting the financial crisis). In years 2 and 3, the difference is around $50,000 \mathrm{DKK}$ - more than $10 \%$ of the average gross individual income. Looking at the average disposable household income, the fluctuations are considerably smaller peaking around 20,000 DKK in period 2, see Figure 3.

The unemployment rate was, by choice-of-sample, zero for the three years up to plant closure. This means that, following Browning and Heinesen (2012) we have a highly selected sample of individuals with a core attachment to the labor market. We also note that although everyone in the treatment group becomes displaced, the vast majority (more than 92\%) nevertheless have a job i November the following year (where the unemployment is measured). Still, those who experience plant closure obtain lower annual earnings in years 1-3 - either because of a lower wage and/or because employment is only part of the year.

[Figure 2-4 about here]

The important point to note here is that plant closure does appear to mimic an exogenous shock and that the treatment and control groups seemingly can be meaningfully compared. 


\section{Estimation Results}

\subsection{Estimation Properties}

Our identification strategy relies on unconfoundedness for the matching estimator to be unbiased. It is therefore important to verify common support and balancing properties, see Table 3 and Figures 5-6. Firstly, note that the values of the lagged dependent variables are virtually identical between treatment and control groups. This is reassuring. Almost all other variables have a percentage bias in the balancing below 5 , a threshold suggested by Caliendo \& Kopeinig (2008) and references therein.

[Table 3 and Figure 5-6 about here]

To check the balancing properties, we calculated two-sample t-statistics and standardized differenes in means for the explanatory variables of the propensity score funtion. The balancing properties are very good and tstatistics consequently very small. Any remaining differences should be picked up by the subsequent linear regression.

\subsection{Overall Effect of Job Displacement}

The average treatment of the treated (ATT) effect of displacement is estimated for both dental care and visits to GP.

We find that displacement leads to a statistically significant decrease in own expenditures on preventive dentist visits of $17 \mathrm{DKK}$ in periods 1 and 2 and 29 DKK in period 3, see Table 4. This drop is equivalent to $6-10 \%$ of the average total expenditures on preventive dental health care. The overall average use of curative dental services decreases significantly in period 2, which in turn also drives the estimated total effect for expenditures on dental care to become significant in period 2 , while insignificant in periods 1 and 3 .

[Table 4 about here]

On average, the same shock has no effect on the use of GP, and the parameter estimates are highly insignificant across all periods.

\subsection{Analysis of a Social Gradient}

Next, we seek to test more of the theoretical predictions listed in Section 2. One important question is whether there is a social gradient in the impact of 
displacement on use of health services, whereby the behavioral response to displacement is stronger for individuals with low SES. In order to investigate this dimension, we divide the sample by income levels. We form three income groups: the lowest income quartile (lowest 25\%), below the median and above the median. ${ }^{17}$

Note that the initial (period 0) level of expenditures on dentists differ between these income groups, see Table 5 . The overall average private expenditures on dentists are 482 DKK, but the average for individuals in households above the median household income is 521 DKK, while it is 439 DKK on average for households below the median and slightly lower for the lowest $25 \%$ (the lowest quartile).

[Table 5-6 about here]

The decrease in preventive dental care is found to be significant not only in total (Table 4) but also across all three income groups and all three periods following plant closure. This is most pronounced in periods 2 and 3 , see Table 6 . In absolute amounts, the average response to displacement is in the range of 13 DKK to 31 DKK. However, since the average initial expenditures on dentists increase with income group the relative response to displacement is magnified for the lower income group. In relative terms, the average decrease in private expenditures on preventive dental service is in the range of $4 \%$ to $11 \%$. This range is relatively stable across the three income groups, though slightly higher for the lowest income groups.

[Table 7 about here]

curative dental care (as defined here) is expected to have a lower intertemporal substitution. One cannot simply postpone the need for curative dental care to the same degree as preventive dental treatment. For the overall sample, we nevertheless found a statistically significant decrease in the use of curative dental care in period 2. Splitting the analysis by income groups reveals that this overall result is driven by a relatively large decrease in the curative dental expenditures on the group of workers with a household income in the lowest $25 \%$ of the sample. For this group, we find an average decrease in the use of curative dental care of $45 \mathrm{DKK}$, which is equivalent to

\footnotetext{
${ }^{17}$ In other words, these groups are not mutually exclusive, since individuals in the lowest quartile also are included among those below the median. The income concept here is household income scaled in adult equivalents.
} 
a relative reduction of $25 \%$ vis-à-vis their average expenditures on curative dental care in the year prior to displacement.

Browning and Crossley (2009) find that intertemporal consumption smoothing of non-durables occurs when households experience a temporary drop in income of $20 \%$ or more. Taking their finding to our setting, we investigate whether the reduction in the expenditures on curative dental care hinges on the drop in disposable household income rather than their initial place in the income distribution, see Table $8 .{ }^{18}$ When the income measure is disposable household income (subjected to the OECD equivalence scale), there is no significant reduction in the expenditures on curative dental care, irrespective of whether the shock to income is above or below a $20 \%$ reduction. However, if the income measure applied is the individual gross income then the results do appear to somewhat corroborate Browning \& Crossley's $20 \%$ threshold, see Table 9 . Using changes in individual gross income, we find that individuals with a decrease in income above the threshold of $20 \%$ decrease their expenditures on curative dental care by 43 DKK in period 2 . For periods 1 and 3, the parameter estimates are highly insignificant.

[Table 8-9 about here]

The use of GPs in response to displacement is estimated to be insignificantly different from zero across the three income groups, as it was also found to be overall.

\section{Discussion}

How do our findings square with theory and expectations? The broad picture largely lends support to the theoretical predictions, although some results are not in full compliance with theory.

Firstly, there is no statistically significant effect of displacement on the use of GPs; not overall, nor for any subgroup analyzed here. According to theory, we could have expected to see a small increase for three reasons: displacement is stressful and can give a shock to health; GP visits are free of

\footnotetext{
${ }^{18}$ Endogeneity is likely an issue here since we condition on future income. In practice, we condition on the size of a drop in income in the treatment group but include the entire control group in the double robust matching estimation. Given the exogenous displacement shock this endogeneity problem is likely relatively small. Sullivan \& von Wachter make similar computations.
} 
charge; and time expenditures decrease if one becomes unemployed. However, our sample consists of displaced workers with a close attachment to the labor market - in the three years prior to plant closure, they all worked full time. This is probably one reason why more than $92 \%$ of them find a job almost immidiately, and for these reasons it is not surprising that we fail to find an increase in the expenditures to GPs. ${ }^{19}$

Secondly, private expenditures on preventive dental care decrease as a result of displacement. The drop is found to be $4 \%-11 \%$ in each of the three years after displacement and to be rather stable across the three income groups analyzed here, though with a slightly larger relative reduction for low income households vis-à-vis households with an income above the median. Preventive dental care can be seen as an investment, much like a durable good, and preventive dental care is therefore expected to be a consumption good with high intertemporal substitution. Our findings support this observation.

Thirdly, we find intuitive albeit mixed results concerning a drop in curative dental care. Browning \& Crossley (2009) underscore the importance of the magnitude of the decrease in income and suggest that a decrease in earnings of $20 \%$ or more will result in a drop in consumption of nondurables, such as curative dental care. Based on individual gross income, there is some evidence in favor of this hypothesis (period 2 only), while the $20 \%$ divide based on household income results in insignificant effects of displacement on curative dental care. Expenditures on curative dental care, on the other hand, decrease for the lowest $25 \%$ household incomes, based on their income in the year prior to plant closure. Thus, we find evidence of a social gradient whereby low income households respond more strongly than high income households. In sum, these findings indicate that consumption smoothing depends not only on the magnitude of the shock but also the initial level of income.

Our results are largely in line with the results from the Rand Health Insurance Experiment. Manning et al. (1987), for instance, found that an insurance that only covered catastrophies reduced expenditures 31 percent relative to a zero out-of-pocket insurance. In our study, the mirror image of this result is that the expenditures to GPs are unaltered by displacement while expenditures to dentists are reduced. Overall, a reduction in the range of 5-10 percent. Manning et al. (1985) also find a social gradient in the use of dental service in response to different insurance conditions, quite comparable

\footnotetext{
${ }^{19}$ A similar absence of causal effects has previously been found in the literature, e.g. Eliason and Storrie (2010).
} 
to what we find. However, they do not that curative and preventive, routine prophulaxis differ. Given the link to intertemporal substitution patterns, our finding that curative dental treatment only decrease for the lowest $25 \%$ income group appear both intuitive and within reasonable ranges.

In monetary terms, the parameter estimates may appear very low and of little economic importance. This is also partly the case, but it should be remembered that the estimates are averages and the variation is substantial. Many people (more than 25 percent of our population) have zero spending on dentists and/or no use of GPs with-in a given year. More importantly, the causal effects in relative terms are non-neglible - in particular the drop in curative dental treatment in period 2 for the group in the lowest income quartile. Lastly, our findings serve as a good example of the importance of intertemporal consumption smoothing in health service utilization, and we are able to estimate significant patterns, irrespective of the relatively low share in households' budgets.

Policy Implications The findings here are of relevance to the discussion of financial support and user charges in health care. One motivating idea behind this paper is the question of user charges for visits to GP. While many countries, including Scandinavian welfare states such as Sweden, Norway and Finland, have introduced user charges, GP visits remain free of charge in Denmark. However, recent political debate has questioned whether user charges for GP visits should be introduced and/or whether financial aid for dental care should be increased, possibly based on increased public revenue from GP user charges. Relevant for this discussion is the overall finding here that user charges do seem to matter. Displaced workers experience a shock and increased risk of stress symptoms. The role of stress in inflammatory disease, including periodontal disease, LeResche \& Dworkin (2002), suggests that dental health would suffer alongside a detoriation in general health. Nevertheless, the use of preventive health decreases while the use of GP stays constant. This difference can most likely be linked to the difference in user charges.

Is it of special concern if people smooth consumption of health care? Possible long-term health effects aside, the welfare loss due to a decrease in expenditures on dentists is low, if preventive treatment is able to 'absorb' the displacement shock. However, curative dental treatment must be characterized as a consumption good with very low intertemporal substitution, and, consequently, the welfare loss induced by a drop in curative treatment, be it due to large shocks and/or low income, is severe. 
There are lots of opportunities for prevention, and some of them might actually save money. Reviews suggest flouridation is the most cost effective, beating sealants, peridontals and restorations, White et al. (1989), Yule et al. (1986), Mitchell and Munay (1989), Antczak-Bouckoms et al. (1989). However, the evidence basis is weak, with very few measures for example using expected quality adjusted tooth years, Birch (1986). That many health insurance plans in the US have zero co-payment for preventative dental care suggests they may be total dental expenditure reducing. If the public support is too generous it can induce moral hazardous behavior. While we touch upon this issue here we cannot ascertain whether the current Danish level of public support for preventive treatment is well balanced.

The social-gradient result, however, and the welfare consequences it bears provides an argument for discriminatory (public) insurance whereby the curative treatment is more generously covered. The policy response could be to link public subsidies to curative treatment conditional on economic circumstances with the caveat that this type of means-tested benefits also have a well-known downside related to implicit high effective tax rates when there are kinks in the eligibility for public financial support. Note also, that our sample consists of individuals with an initial core attachment to the labor market (full time employed for three consecutive years prior to displacement) and most quickly find a new, albeit perhaps less lucrative, job. The result, therefore, is not linked to individuals in the very low end of the income distribution of the entire population. Means-testing therefore requires additional analysis of behavior among the lowest income group in the population.

Private-based insurance may seem as an obvious alternative solution, but given the revealed preferences for not choosing this in the first place, such a policy would require some degree of paternalistic Government setting a minimum requirement of self-insurance, which does not appear likely. ${ }^{20}$

\section{Conclusion}

The main contribution of this paper is the comparison of behavioral responses for two different outcomes to the same displacement shock. One outcome is public expenditures to GP visits and the other is partly selffinanced dentist expenditures. This simple setting allows for an assessment of the importance of user charges. The results suggest that user charges do

\footnotetext{
${ }^{20}$ See Le Grand and New (2015) for interesting discussions of Government paternalism including a discussion of conditions under which paternalistic policies are justified.
} 
matter; that most behavioral response is through a decrease in preventive dental treatment, but for low income households, or households where the shock to individual gross income is beyond $20 \%$, there is also a drop in curative dental care, which arguably has a large welfare loss attached. While most findings are much in line with the well-known Rand Health Insurance Experiment, this difference in behavioral response to preventive and curative dental service, also expected from theory, is a new finding. Like Manning et al. $(1985,1987)$ we argue that insurance does not need to be uniform across various medical services. Instead, coverage could be more generous for $\mathrm{cu}-$ rative dental care. The policy implications could be means-tested financial support for curative dental care. 


\section{References}

Antczak-Bouckoms, A.A., J.F.C. Tulloh, B.A. White \& E.I. Capilouto (1989). Methodological considerations in the analysis of cost-effectiveness in dentistry. Journal of Public Dental Health, 49:215-222.

Arrow, K. J. (1963). Uncertainty and the Welfare Economics of Medical Care. American Economic Review, 53(5): 941-973.

Birch, S. (1986). Measuring dental health: Improvements on the DMFindex. Community Dental Health, 3:303-311.

Browning, M. \& T. F. Crossley (2000). Luxuries are Easier to Postpone: A Proof. Journal of Political Economy, 108(5): 1064-1068.

Browning, M. \& T. F. Crossley (2001). Unemployment Insurance Levels and Consumption Changes. Journal of Public Economics, 80(1): 1-23.

Browning, M. \& T. F. Crossley (2009). Shocks, Stocks, and Socks: Smoothing Consumption over a Temporary Income Loss. Journal of the European Economic Association, 7(6): 1169-1192.

Browning, M. \& E. Heinesen (2012). Effect of job loss due to plant closure on mortality and hospitalization. Journal of Health Economics, 31: 599-616.

Caliendo, M. \& S. Kopeinig (2008). Some Practical Gudiance for the Implementation of Propensity Score Matching. Journal of Economic Surveys, 22(1): 31-72.

Chabé-Ferret, S. (2015). Analysis of the Bias of Matching and DifferenceIn-Difference under Alternative Earnings and Selection Processes. Journal of Econometrics, 185(1): 110-123.

Clark, A.E., Y. Georgellis \& P. Sanfey (2001). Scarring: The Psychological Impact of Past Unemployment. Economica, 68: 221-241.

Clark, D. \& H. Royer (2013). The Effect of Education on Adult Mortality and Health: Evidence from the United Kingdom. American Economic Review, 103(6): 2087-2120. 
Coffey R. M. (1983). The Effect of Time Price in the Demand for Medical Care Services. Journal of Human Resources 18(3): 407-424.

Cutler, D. M. \& A. Lleras-Muney (2007). Education and Health: Evaluating Theories and Evidence. In J. S. House, G. A. Kaplan, and H. Pollack (eds.): The Health Effects of Social and Economic Policy. New York: Russel Sage Foundation.

Eliason, M. \& D. Storrie (2006). Lasting or latent scars? Swedish evidence on the long-term effects of job displacement. Journal of Labor Economics, 24 (4), 831-856.

Eliason, M. \& D. Storrie (2009a). Does job loss shorten life? Journal of Human Resources, 44 (2), 277-302.

Eliason, M. \& D. Storrie (2009b). Job loss is bad for your health - Swedish evidence on cause-specific hospitalization following involuntary job loss. Social Science and Medicine, 68, 1396-1406.

Eliason, M. \& D. Storrie (2010). Inpatient psychiatric hospitalization following involuntary job loss. International Journal of Mental Health, 39 (2), $32-55$.

Emsley, R., M. Lunt, A. Pickles \& G. Dunn (2008). Implementing doublerobust estimators of causal effects. Stata Journal, 8(3): 334-353.

Grossman, M. (1972). On the Concept of Health Capital and the Demand for Health. Journal of Political Economy, 80(2): 223-255.

Grossman, M. \& E. H. Rand (1974). Incentives for Health Services in Chronic Illness. In S. J. Mushkin (ed.) Consumer Incentives for Health Care, Prodist, New York.

Gruber, J. (1997). The Consumption Smoothing Benefits of Unemployment Insurance. American Economic Review, 87(1): 192-203.

Hamermesh, D. S. (1982). Social Insurance and Consumption: An Empirical Inquiry. American Economic Review, 72(1): 101-113.

Hijzen, A., R. Upward \& P.W. Wright (2010). The income losses of dis- 
placed workers. Journal of Human Resources, 45(1): 243-269.

Hirano, K. \& G. W. Imbens (2001). Estimation of causal effects using propensity score weighting: an application to data on right heart catherization. Health Services \&5 Outcomes Research Methodology, 2: 259-278.

Ho, D. E., K Imai, G. King \& E.A. Stuart (2007). Matching as Nonparametric Preprocessing for Reducing Model Dependence in Parametric Causal Inference. Political Analysis, 15:199-236

Imbens, G. W. \& J. M. Wooldridge (2009). Recent Developments in the Econometrics of Program Evaluation. Journal of Economic Literature, 47(1): $5-86$.

Kenkel, D. S. (2000). Prevention. Handbook of Health Economics, 1B, ch. 31: 1676-1714.

Kessler, R.C., Turner, J.B. \& House, J.S. (1987). Intervening processes in the relationship between unemployment and health. Psychological Medicine, 17(4): 949-961.

Le Grand, J. \& B. New (2015). Government Paternalism. Princeton University Press, Princeton \& Oxford.

LeResche, L. \& S. F. Dworkin (2002). The role of stress in inflammatory disease, including periodontal disease: review of concepts and current findings. Periodontology 2000, 30(1): 91-103.

Manning, W. G., B. Benjamin, H. L. Bailit \& J.P Newhouse (1985). The Demand for Dental Care: Evidence From a Randomized Trial in Health Insurance. Journal of the American Dental Association, 110:895-902.

Manning, W. G., J. P. Newhouse, N. Duan, E. B. Keeler, A. Leibowitz \& M. S. Marquis (1987). Health Insurance and the Demand for Medical Care: Evidence from a Randomized Experiment. American Economic Review, 77(3): 251-277.

Mitchell, L., \& J. Munay (1989). Fissure sealants: A critique on their costeffectiveness. Community Dentistry and Oral Epidemiology, 17:19-23. 
Morris, J. K. \& D. G. Cook (1991). A Critical Review of the Effect of Factory Closures on Health. British Journal of Industrial Medicine, 48(1):1-8.

Mushkin, S. J. (1962). Health as an Investment. Journal of Political Economy, 70(2): 129-157.

Parker, J. (1999). The Reaction of Household Consumption to Predictable Changes in Payroll Tax Rate. American Economic Review, 89(4): 959-973.

Rotnitzky, A. \& J.M. Robins (1995). Semiparametric regression estiamtion in the presence of dependent censoring. Biometrika, 82(4): 805-820.

Ruhm, C.J. (1991). Displacement Induced Joblessness Review of Economics and Statistics, 73(3): 517-522.

Simonsen, M., L. Skipper \& N. Skipper (2015). Price Sensitivity of Demand for Prescription Drugs: Exploiting a Regression Kink Design. Forthcoming, Journal of Applied Econometrics.

Sintonen, H. \& I. Linnosmaa (2000). Economics of Dental Services. Handbook of Health Economics, 1B, ch. 31: 1252-1292.

Sullivan, D. \& T. von Wachter (2009). Job Displacement and Mortality: An Analysis Using Administrative Data. Quarterly Journal of Economics, 124(3): 1265-1306.

White, B.A., A.A. Antczak-Bouckoms \& M.C. Weinstein (1989). Issues in the economic evaluation of community water fluoridation. Journal of Dental Education, 53:646-657.

Yule, B.E., B.M. van Amerongen \& M.C.M. van Schaik (1986). The economics and evaluation of dental care and treatment. Social Science and Medicine, 22:1131-39. 
Table 1 Costs to dentist and GP, by displacement group (DKK)

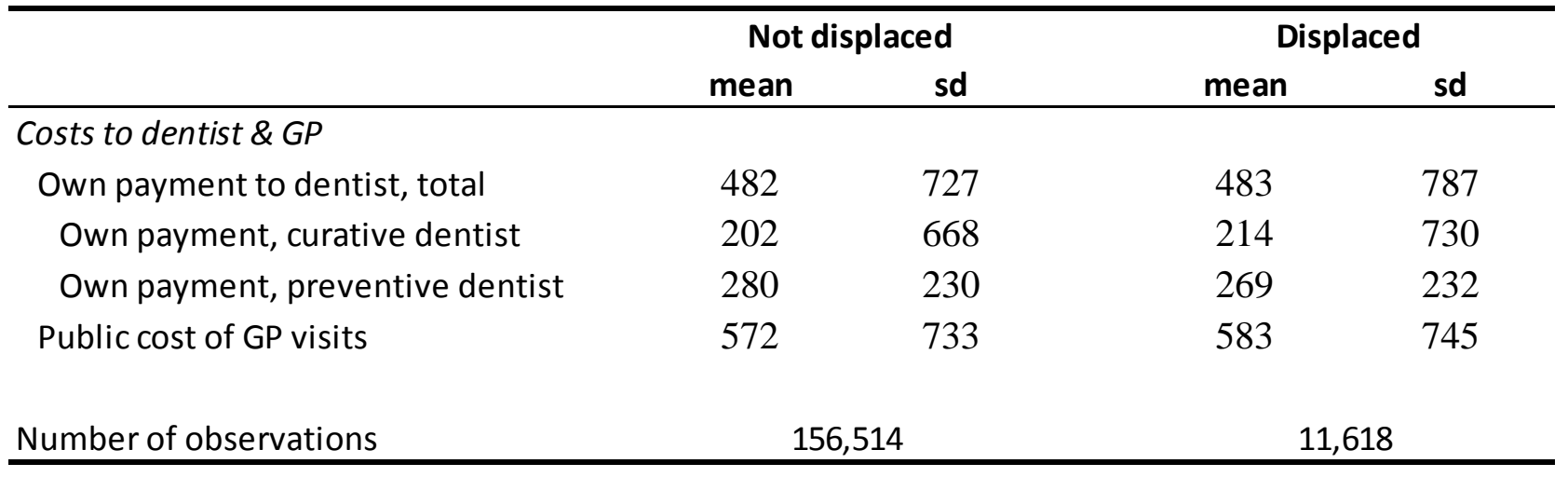

Note: The sample here is conditioned on the year prior to plant closure.

Figure 1 Distribution of Expenditures to Health Care, Dentist and GP (DKK)

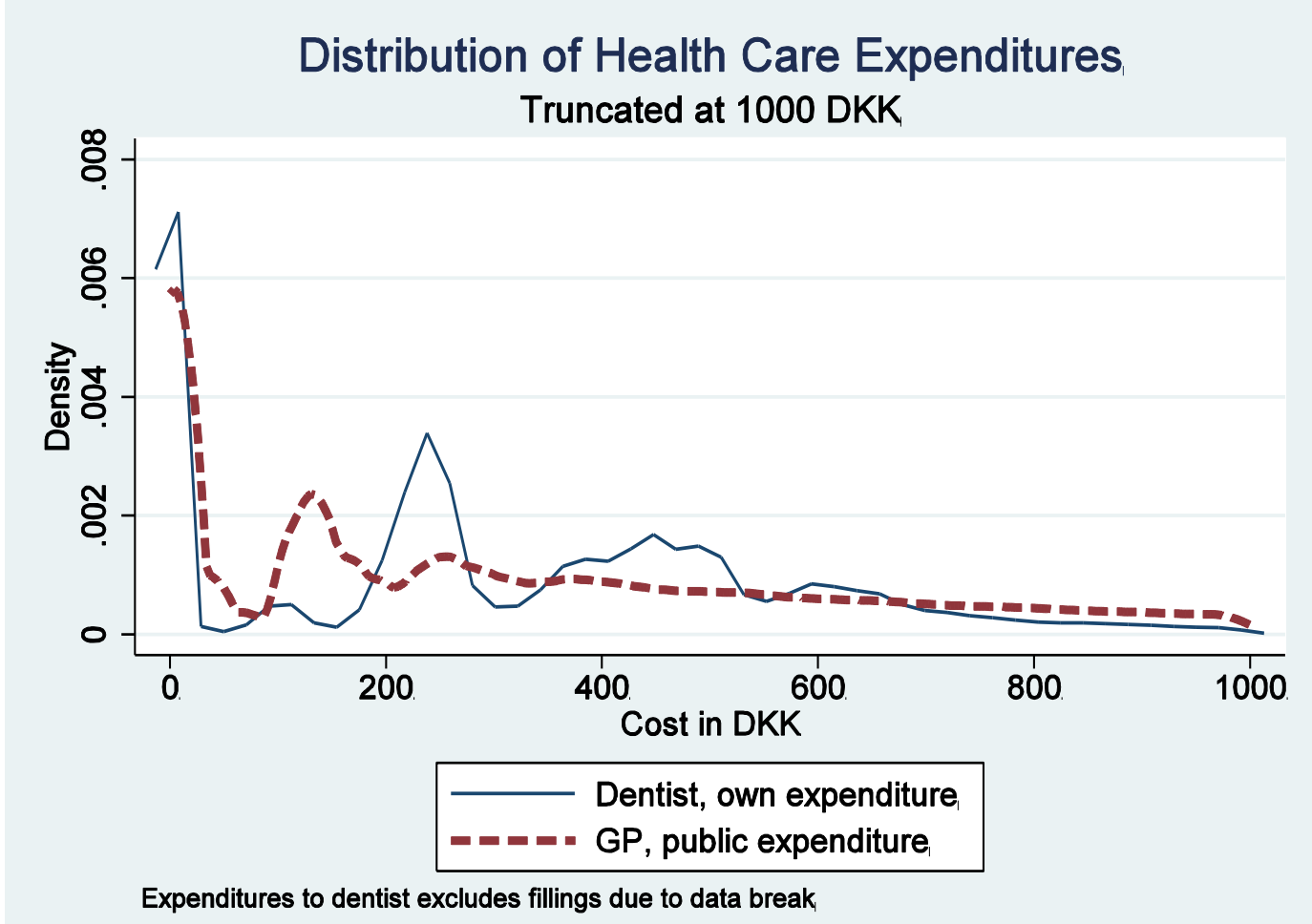

Note: 1 USD equals approximately 5.6 DKK during the years covered in the sample. 
Table 2 Descriptive statistics, by displacement group

\begin{tabular}{|c|c|c|c|c|}
\hline & \multicolumn{2}{|c|}{ Not displaced } & \multicolumn{2}{|c|}{ Displaced } \\
\hline & mean & sd & mean & sd \\
\hline \multicolumn{5}{|l|}{ Household \& individual characteristics } \\
\hline Female & 0.30 & 0.46 & 0.30 & 0.46 \\
\hline \multicolumn{5}{|l|}{ Age } \\
\hline $20-29$ & 0.09 & 0.28 & 0.07 & 0.26 \\
\hline $30-34$ & 0.12 & 0.33 & 0.12 & 0.33 \\
\hline $35-39$ & 0.16 & 0.37 & 0.16 & 0.36 \\
\hline $45-49$ & 0.15 & 0.36 & 0.15 & 0.36 \\
\hline $50-54$ & 0.13 & 0.34 & 0.15 & 0.35 \\
\hline $55-60$ & 0.17 & 0.38 & 0.18 & 0.38 \\
\hline Education (years) & 12.66 & 2.31 & 12.42 & 2.38 \\
\hline Education<12 years (dummy) & 0.28 & 0.45 & 0.32 & 0.47 \\
\hline \multicolumn{5}{|l|}{ Homeliving children } \\
\hline \multicolumn{5}{|l|}{ Family structure (ref: single parent) } \\
\hline single, no children & 0.19 & 0.39 & 0.20 & 0.40 \\
\hline married/cohab., no children & 0.33 & 0.47 & 0.34 & 0.47 \\
\hline married/cohab., with children & 0.45 & 0.50 & 0.43 & 0.50 \\
\hline Household eq. disp. Inc. (10,000 DKK) & 22.96 & 11.16 & 22.66 & 11.31 \\
\hline \multicolumn{5}{|l|}{ Tenure (ref: more than 7)) } \\
\hline 3 years & 0.19 & 0.39 & 0.18 & 0.39 \\
\hline 4 years & 0.13 & 0.33 & 0.14 & 0.35 \\
\hline 5 years & 0.10 & 0.30 & 0.10 & 0.29 \\
\hline 6 years & 0.08 & 0.27 & 0.09 & 0.28 \\
\hline 7 years & 0.07 & 0.25 & 0.07 & 0.25 \\
\hline Dummy for annual UE degree (ref=0) & 0.95 & 0.21 & 0.92 & 0.27 \\
\hline \multicolumn{5}{|l|}{ Industry } \\
\hline manufacturing, food, beverages etc. & 0.02 & 0.14 & 0.03 & 0.18 \\
\hline manufacturing, wood, paper, printing etc. & 0.03 & 0.17 & 0.04 & 0.20 \\
\hline manufacturing, chemicals & 0.04 & 0.20 & 0.04 & 0.20 \\
\hline manufacturing, metals and machinery & 0.17 & 0.38 & 0.10 & 0.30 \\
\hline manufacturing, other & 0.01 & 0.12 & 0.01 & 0.09 \\
\hline construction & 0.24 & 0.42 & 0.22 & 0.41 \\
\hline trade/transport & 0.08 & 0.26 & 0.08 & 0.28 \\
\hline financial and business services & 0.10 & 0.31 & 0.15 & 0.36 \\
\hline other industries & 0.11 & 0.31 & 0.11 & 0.31 \\
\hline Continued next page & & & & \\
\hline
\end{tabular}




\begin{tabular}{|c|c|c|c|c|}
\hline \multirow[b]{2}{*}{ Continued from above } & \multicolumn{2}{|c|}{ Not displaced } & \multicolumn{2}{|c|}{ Displaced } \\
\hline & mean & sd & mean & sd \\
\hline \multicolumn{5}{|l|}{ Occupation (ISCO codes) } \\
\hline high level employee & 0.07 & 0.26 & 0.06 & 0.23 \\
\hline middle level employee & 0.14 & 0.34 & 0.11 & 0.31 \\
\hline office and customer service & 0.10 & 0.30 & 0.10 & 0.30 \\
\hline service and sales & 0.03 & 0.18 & 0.02 & 0.15 \\
\hline agriculture etc. & 0.01 & 0.08 & 0.01 & 0.08 \\
\hline craftsman-like & 0.24 & 0.43 & 0.23 & 0.42 \\
\hline operatoer/transport & 0.09 & 0.28 & 0.09 & 0.29 \\
\hline military & 0.11 & 0.31 & 0.12 & 0.32 \\
\hline other manual & 0.17 & 0.37 & 0.23 & 0.42 \\
\hline \multicolumn{5}{|l|}{ Region of living } \\
\hline Copenhagen & 0.07 & 0.26 & 0.08 & 0.27 \\
\hline Greater Cph. area & 0.08 & 0.27 & 0.08 & 0.27 \\
\hline North Sealand & 0.09 & 0.28 & 0.08 & 0.28 \\
\hline Central Sealand & 0.01 & 0.09 & 0.00 & 0.06 \\
\hline South Sealand & 0.05 & 0.21 & 0.05 & 0.22 \\
\hline Fuenen & 0.10 & 0.30 & 0.12 & 0.32 \\
\hline South Jutland & 0.14 & 0.35 & 0.14 & 0.34 \\
\hline Central Jutland & 0.15 & 0.36 & 0.15 & 0.36 \\
\hline West Jutland & 0.10 & 0.30 & 0.09 & 0.28 \\
\hline North Jutland & 0.12 & 0.32 & 0.11 & 0.31 \\
\hline Individuals & 155,139 & & 11,493 & \\
\hline
\end{tabular}

Note: The sample here is conditioned on the year prior to plant closure. 
Figure 2 Average individual gross earnings, by displacement group (DKK)

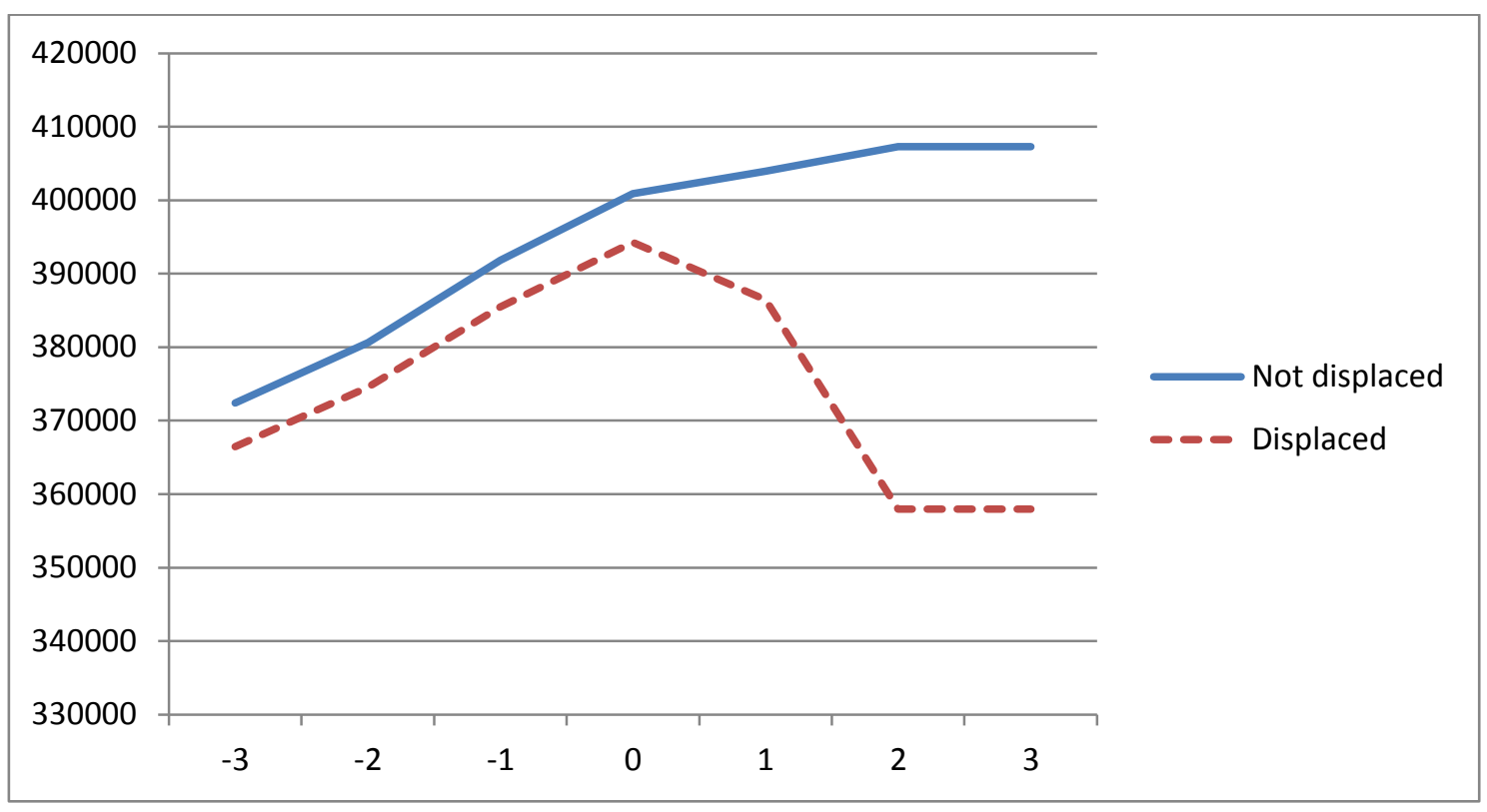

Note: plant closure at $\mathrm{t}=1$.

Figure 3 Average household disposable income, by displacement group (DKK)

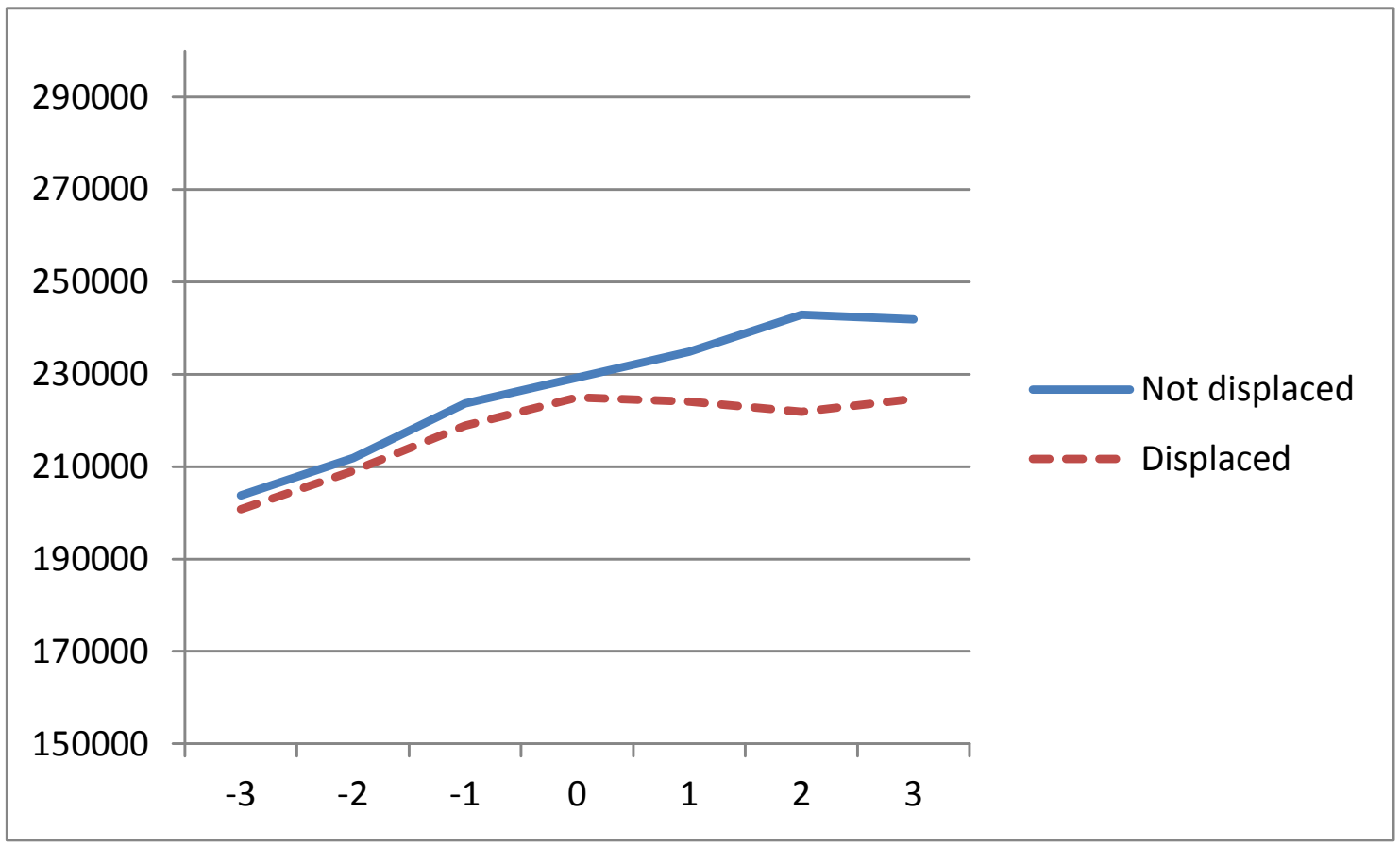

Note: plant closure at $\mathrm{t}=1$. Disposable household income measured in OECD adult equivalents. 
Figure 4 Average unemployment rate, by displacement group

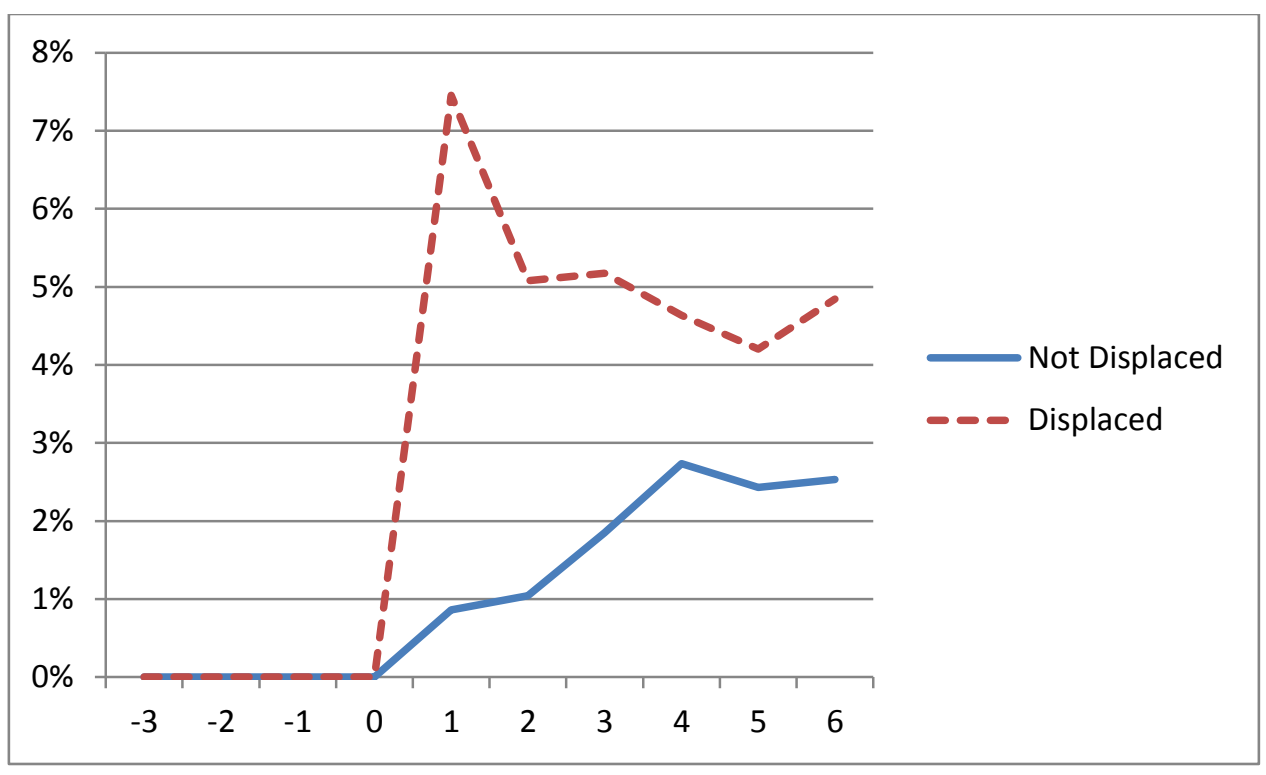

Note: plant closure at $\mathrm{t}=1$. 
Table 3 Balancing properties with respect to the explanatory variables of the propensity score, by treated and control groups

\begin{tabular}{|c|c|c|c|c|c|}
\hline \multirow[b]{2}{*}{ Variable } & \multicolumn{2}{|c|}{ Mean } & \multirow[b]{2}{*}{ \%bias } & \multirow[b]{2}{*}{ t-test } & \multirow[b]{2}{*}{$p>|t|$} \\
\hline & Treated & Control & & & \\
\hline Own cost dentist t-3 & 403.920 & 413.240 & -1.400 & -0.590 & 0.553 \\
\hline Own cost dentist t-2 & 464.070 & 478.180 & -2.000 & -0.790 & 0.431 \\
\hline own cost dentist $\mathrm{t}-1$ & 464.490 & 461.090 & 0.500 & 0.200 & 0.844 \\
\hline Cost GP t-3 & 502.580 & 505.470 & -0.400 & -0.170 & 0.866 \\
\hline Cost GP t-2 & 502.940 & 509.940 & -1.100 & -0.450 & 0.649 \\
\hline Cost GP t-1 & 551.940 & 545.830 & 0.900 & 0.370 & 0.710 \\
\hline In Household annual income t-1 & 3.034 & 3.032 & 0.800 & 0.340 & 0.734 \\
\hline \multicolumn{6}{|l|}{ Age group (ref=40-44) } \\
\hline age20_29 & 0.055 & 0.057 & -0.500 & -0.210 & 0.833 \\
\hline age30_34 & 0.120 & 0.121 & -0.100 & -0.040 & 0.970 \\
\hline age35_39 & 0.164 & 0.162 & 0.300 & 0.130 & 0.896 \\
\hline age45_49 & 0.159 & 0.159 & 0.200 & 0.070 & 0.947 \\
\hline age50_54 & 0.139 & 0.141 & -0.800 & -0.310 & 0.754 \\
\hline age55_60 & 0.180 & 0.183 & -0.600 & -0.250 & 0.802 \\
\hline Female $(=1)$ & 0.319 & 0.316 & 0.700 & 0.290 & 0.775 \\
\hline \multicolumn{6}{|c|}{ Tenure group (ref= more than 7 years) } \\
\hline tenure 3 years & 0.179 & 0.166 & 3.300 & 1.440 & 0.149 \\
\hline tenure 4 years & 0.134 & 0.137 & -0.900 & -0.350 & 0.723 \\
\hline tenure 5 years & 0.091 & 0.084 & 2.600 & 1.070 & 0.284 \\
\hline tenure 6 years & 0.080 & 0.091 & -3.900 & -1.560 & 0.119 \\
\hline tenure 7 years & 0.069 & 0.069 & 0.000 & 0.000 & 1.000 \\
\hline \multicolumn{6}{|l|}{ Education (ref=primary) } \\
\hline High school & 0.054 & 0.055 & -0.300 & -0.110 & 0.915 \\
\hline Skilled worker & 0.521 & 0.530 & -1.800 & -0.730 & 0.467 \\
\hline College & 0.068 & 0.061 & 2.800 & 1.230 & 0.218 \\
\hline Bachelor & 0.058 & 0.051 & 2.800 & 1.230 & 0.220 \\
\hline Master or higher & 0.059 & 0.058 & 0.400 & 0.150 & 0.877 \\
\hline \multicolumn{6}{|c|}{ Family structure (ref=single parent with kids) } \\
\hline Single parent, no kids & 0.182 & 0.190 & -2.100 & -0.840 & 0.401 \\
\hline Couple, no kids & 0.329 & 0.329 & -0.100 & -0.050 & 0.959 \\
\hline Couple, with kids & 0.458 & 0.451 & 1.500 & 0.610 & 0.543 \\
\hline Ethnic dane & 0.945 & 0.943 & 1.100 & 0.420 & 0.674 \\
\hline
\end{tabular}

(continued next page) 


\begin{tabular}{|c|c|c|c|c|c|}
\hline \multicolumn{6}{|l|}{ Geographic place of residence (ref=Fuenen) } \\
\hline Copenhagen & 0.076 & 0.081 & -1.800 & -0.720 & 0.471 \\
\hline Nord sealand & 0.084 & 0.075 & 3.100 & 1.340 & 0.180 \\
\hline Bornholm & 0.090 & 0.085 & 1.700 & 0.730 & 0.466 \\
\hline Mid sealand & 0.002 & 0.001 & 1.700 & 1.420 & 0.157 \\
\hline South sealand & 0.069 & 0.062 & 2.900 & 1.170 & 0.242 \\
\hline South jutland & 0.127 & 0.128 & -0.400 & -0.180 & 0.856 \\
\hline Mid jutland & 0.147 & 0.149 & -0.400 & -0.170 & 0.865 \\
\hline West jutland & 0.124 & 0.125 & -0.300 & -0.150 & 0.883 \\
\hline North jutland & 0.087 & 0.091 & -1.100 & -0.470 & 0.640 \\
\hline Type of Occupation (ref=management) & 0.107 & 0.116 & -2.800 & -1.120 & 0.265 \\
\hline Highest level & 0.062 & 0.057 & 1.900 & 0.870 & 0.385 \\
\hline Mid level & 0.122 & 0.118 & 1.000 & 0.450 & 0.655 \\
\hline Office work \& customer support & 0.111 & 0.111 & -0.100 & -0.040 & 0.969 \\
\hline Service and sales & 0.022 & 0.024 & -1.600 & -0.730 & 0.467 \\
\hline Agriculture \& forestry & 0.008 & 0.009 & -1.100 & -0.410 & 0.685 \\
\hline Craftsmanship & 0.190 & 0.193 & -0.700 & -0.280 & 0.782 \\
\hline Operator, Transport & 0.088 & 0.096 & -2.800 & -1.130 & 0.259 \\
\hline Other manual & 0.357 & 0.348 & 2.100 & 0.840 & 0.403 \\
\hline Military & 0.000 & 0.000 & 0.000 & 0.000 & 1.000 \\
\hline Dummy for annual UE degree (ref=0) & 0.950 & 0.953 & -1.400 & -0.560 & 0.574 \\
\hline \multicolumn{6}{|c|}{ Plant industry (ref=service industry except financial) } \\
\hline Manufacturing, food, beverages etc. & 0.012 & 0.013 & -0.400 & -0.220 & 0.826 \\
\hline Manufacturing, wood, paper, printing etc. & 0.059 & 0.060 & -0.400 & -0.150 & 0.878 \\
\hline Manufacturing, chemicals & 0.046 & 0.043 & 1.500 & 0.580 & 0.559 \\
\hline Manufacturing, metals and machinery & 0.087 & 0.092 & -1.400 & -0.640 & 0.525 \\
\hline Manufacturing, other & 0.012 & 0.014 & -2.100 & -0.860 & 0.391 \\
\hline Construction & 0.151 & 0.155 & -1.200 & -0.470 & 0.638 \\
\hline Transport & 0.094 & 0.096 & -0.700 & -0.290 & 0.773 \\
\hline Financial and business services & 0.205 & 0.193 & 3.200 & 1.300 & 0.192 \\
\hline Other industries & 0.069 & 0.069 & -0.100 & -0.050 & 0.962 \\
\hline \multicolumn{6}{|l|}{ Number of employees } \\
\hline $21-50$ & 0.239 & 0.244 & -1.100 & -0.480 & 0.630 \\
\hline $51-100$ & 0.093 & 0.093 & -0.300 & -0.120 & 0.901 \\
\hline 101 or more & 0.126 & 0.119 & 2.000 & 0.890 & 0.375 \\
\hline Local unemployment rate & 1.816 & 1.847 & -3.300 & -1.340 & 0.181 \\
\hline
\end{tabular}

Note: There is exact matching on year, which is why year dummies are not included in the list above. 
Figure 5 balancing properties
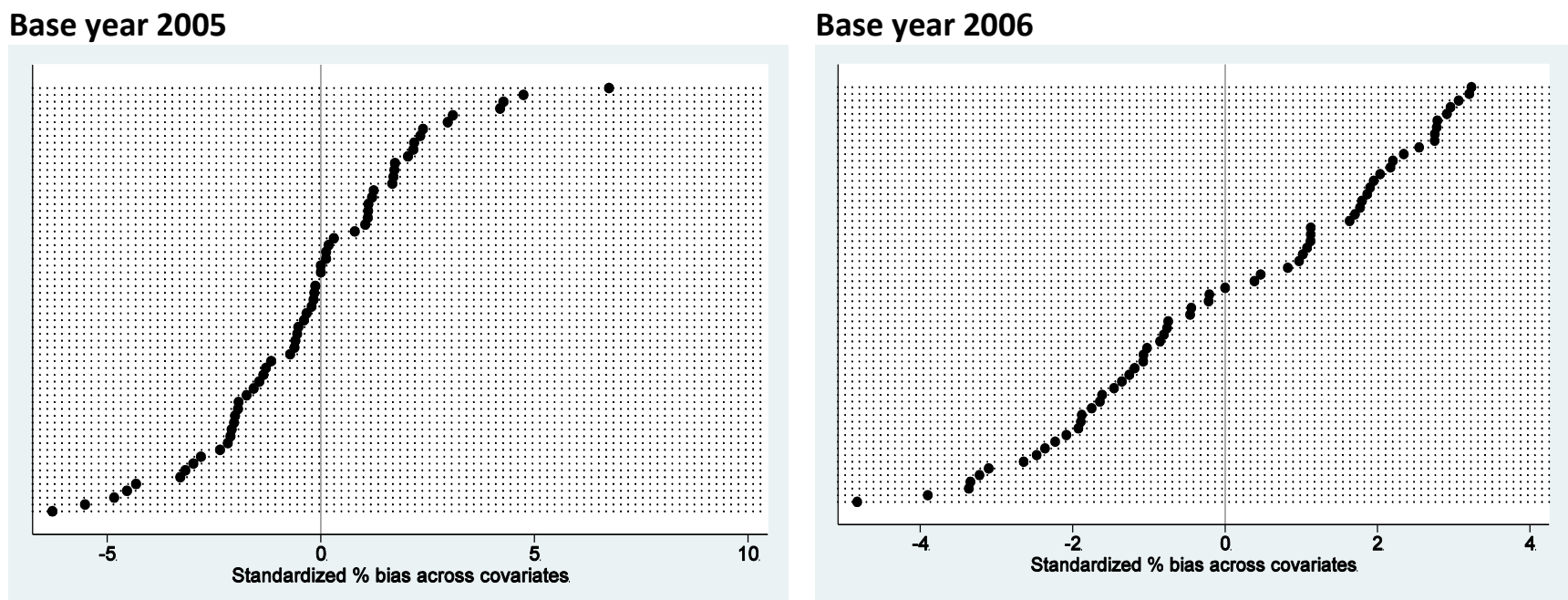

Base year 2007

\section{Base year 2008}
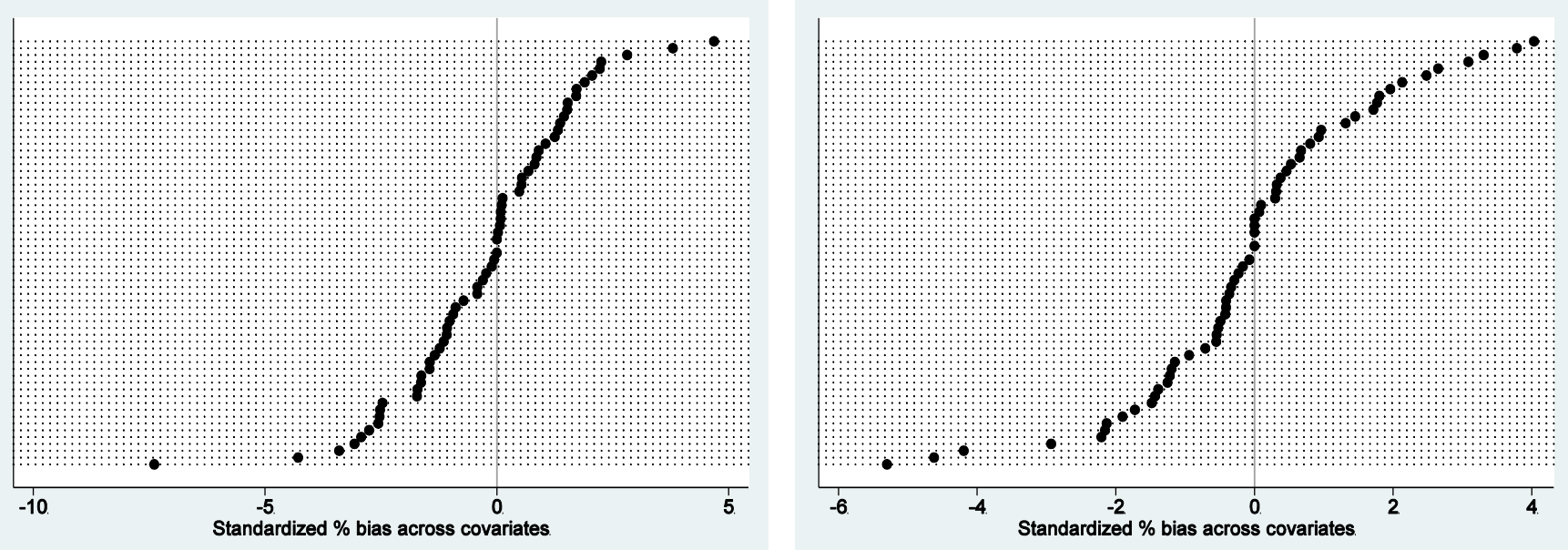

Note: The above graphs are for total dental care; plots for GP are similar. 
Figure 6 Common support

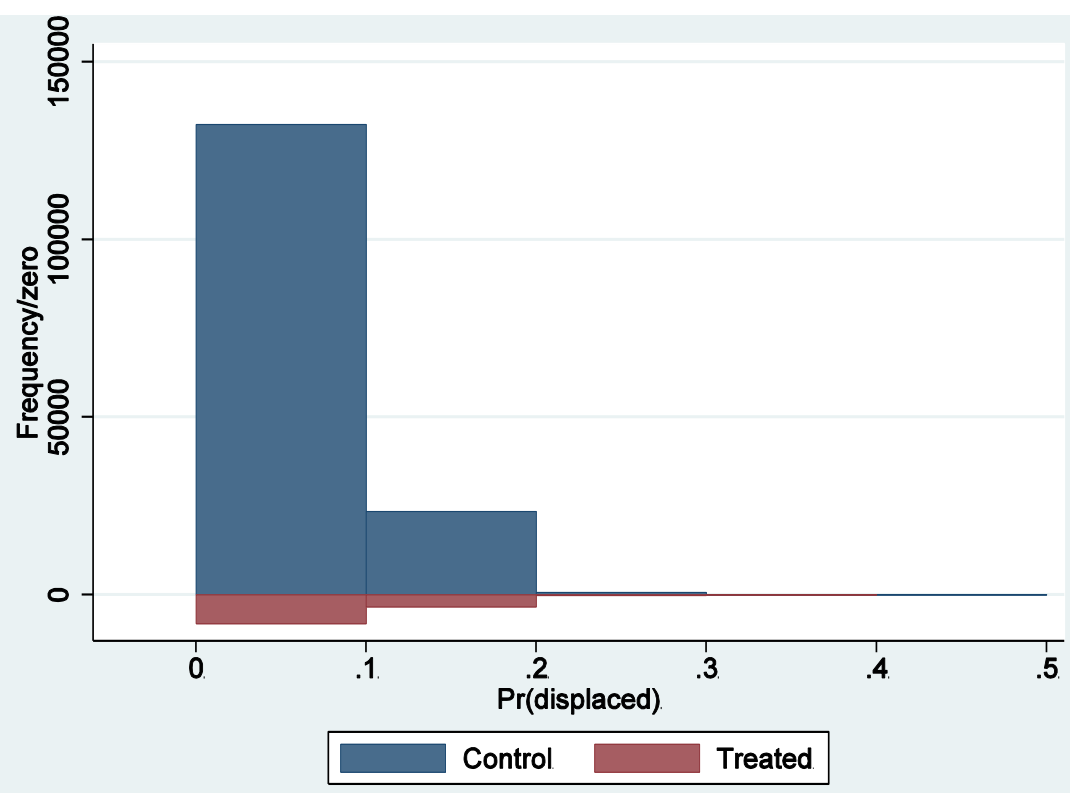

Note: In the estimation we use a caliper and require common support. Very few observations are deleted in this process. 
Table 4 Average treatment of the treated (ATT) for own expenditures to dentist and public expenditures to GP

\begin{tabular}{l|rrrr}
\hline \multirow{2}{*}{ Period } & \multicolumn{3}{|c}{ Dentist } & GP \\
\hline $\mathrm{t}=1$ & Total & Curative & Preventive & Total \\
& -17.56 & -0.55 & $-\mathbf{1 7 . 0 1}$ & -1.88 \\
$\mathrm{t}=2$ & $(14.27)$ & $(15.32)$ & $(3.37)$ & $(17.03)$ \\
& -29.14 & -11.94 & -17.21 & -8.93 \\
$\mathrm{t}=3$ & $(\mathbf{8 . 1 )}$ & $(4.34)$ & $(6.96)$ & $(22.67)$ \\
& -2.93 & 14.37 & -29.38 & -12.40 \\
& $(10.6)$ & $(10.06)$ & $(3.77)$ & $(14.63)$ \\
\hline
\end{tabular}

Note: Significant parameter estimates at the $10 \%$ level (for a two-sided test) in bold. Standard deviations in parentheses.

Table 5 Average Expenditures for Dentists and GPs, by Income Group (DKK)

\begin{tabular}{|c|c|c|c|c|}
\hline \multirow[b]{2}{*}{ Group } & \multicolumn{2}{|c|}{ Dentist } & \multicolumn{2}{|c|}{ GP } \\
\hline & Total & Curative & Preventive & Total \\
\hline All & 482 & 203 & 279 & 573 \\
\hline \multicolumn{5}{|l|}{ Income } \\
\hline Above median & 521 & 223 & 297 & 573 \\
\hline Below median & 439 & 180 & 259 & 572 \\
\hline Lowest quartile & 423 & 178 & 245 & 581 \\
\hline
\end{tabular}

Note: "Income" is the equivalated real (2010) household disposable income. 
Table 6 Average Treatment of Treated on use of Health Care, by income group

\begin{tabular}{|c|c|c|c|c|}
\hline \multirow{2}{*}{$\begin{array}{l}\text { HH Income above median } \\
\text { Period }\end{array}$} & \multicolumn{2}{|c|}{ Dentist } & \multicolumn{2}{|c|}{ GP } \\
\hline & Total & Curative & Preventive & Total \\
\hline \multirow[t]{2}{*}{$t=1$} & -1.7 & 13.5 & -15.2 & -2.0 \\
\hline & $(14.1)$ & $(16.3)$ & $(5.2)$ & $(45.6)$ \\
\hline \multirow[t]{2}{*}{$t=2$} & -20.1 & -7.4 & -12.8 & -14.7 \\
\hline & $(26.1)$ & (19.5) & (7.1) & (39.3) \\
\hline \multirow[t]{2}{*}{$t=3$} & -14.6 & -0.2 & -31.1 & -5.9 \\
\hline & $(35.3)$ & $(20.6)$ & $(14.2)$ & (23.9) \\
\hline \multicolumn{5}{|l|}{ HH income below median } \\
\hline \multirow[t]{2}{*}{$t=1$} & -28.3 & -9.4 & -18.9 & -8.4 \\
\hline & $(18.2)$ & $(18.7)$ & $(0.5)$ & (27.9) \\
\hline \multirow[t]{2}{*}{$t=2$} & -36.2 & -16.5 & -19.7 & -18.5 \\
\hline & $(14.1)$ & (18.9) & $(7.4)$ & $(17.6)$ \\
\hline \multirow[t]{2}{*}{$t=3$} & 2.2 & 23.0 & -26.8 & -19.6 \\
\hline & $(24.9)$ & (23.9) & (4.9) & (14.2) \\
\hline \multicolumn{5}{|l|}{$\mathrm{HH}$ Income in lower quartile } \\
\hline \multirow[t]{2}{*}{$t=1$} & -33.9 & -17.6 & -16.3 & 0.4 \\
\hline & $(35.8)$ & $(33.2)$ & (9.1) & (27.9) \\
\hline \multirow[t]{2}{*}{$t=2$} & -71.9 & -44.8 & -27.0 & 3.9 \\
\hline & (9.6) & (7.3) & (11.7) & (26.8) \\
\hline \multirow[t]{2}{*}{$t=3$} & -5.1 & 13.2 & -23.0 & -7.1 \\
\hline & $(48.3)$ & (50.5) & (9.6) & (34.3) \\
\hline
\end{tabular}

Note: Significant parameter estimates at the $10 \%$ level (for a two-sided test) in bold. Standard deviations in parentheses. 
Table 7 Average Treatment Effect Relative to Initial Expenditures Level, by income group

\begin{tabular}{l|rrr}
\hline HH Income above median & \multicolumn{3}{|c}{ Dentist } \\
Period & Total & Curative & Preventive \\
\hline $\mathrm{t}=1$ & --- & --- & $-5.1 \%$ \\
$\mathrm{t}=2$ & --- & --- & $-4.3 \%$ \\
$\mathrm{t}=3$ & --- & --- & $-10.5 \%$ \\
$\mathrm{HH}$ income below median & & & \\
\hline $\mathrm{t}=1$ & --- & --- & $-7.3 \%$ \\
$\mathrm{t}=2$ & $-8.2 \%$ & --- & $-7.6 \%$ \\
$\mathrm{t}=3$ & --- & --- & $-10.4 \%$ \\
$\mathrm{HH}$ Income in lower quartile & & & \\
\hline $\mathrm{t}=1$ & --- & --- & $-6.6 \%$ \\
$\mathrm{t}=2$ & $-17.0 \%$ & $-25.1 \%$ & $-11.0 \%$ \\
$\mathrm{t}=3$ & --- & --- & $-9.4 \%$ \\
\hline
\end{tabular}

Note: Empty cells where the estimated ATT (Table 6) is insignificant at the $10 \%$ level (for a two-sided test). The GP column is therefore not included. 
Table 8 Average Treatment Effect on Expenditures for Curative Dental Care, by drop in Disposable Household Income

\begin{tabular}{lcc}
\hline Period & $\begin{array}{l}\text { Not 20\% drop in } \\
\text { household income }\end{array}$ & $\begin{array}{l}\text { At least 20\% drop in } \\
\text { household income }\end{array}$ \\
\hline $0-1$ & 4.1 & 30.9 \\
& $(19.6)$ & $(68.3)$ \\
$0-2$ & -10.1 & -13.2 \\
& $(12.6)$ & $(77.7)$ \\
$0-3$ & 17.0 & -5.6 \\
& $(17.7)$ & $(49.6)$ \\
\hline
\end{tabular}

Note: Significant parameter estimates at the $10 \%$ level (for a two-sided test) in bold. Standard deviations in parentheses.

Table 9 Average Treatment Effect on Expenditures for Curative Dental Care, by drop in Individual Gross Earnings

\begin{tabular}{lcc}
\hline Period & $\begin{array}{c}\text { Not 20\% drop in } \\
\text { individual gross } \\
\text { income }\end{array}$ & $\begin{array}{c}\text { At least 20\% drop in } \\
\text { individual gross } \\
\text { income }\end{array}$ \\
\hline $0-1$ & 2.2 & 19.8 \\
& $(16.8)$ & $(37.9)$ \\
$0-2$ & -6.4 & -43.5 \\
& $(5.5)$ & $(25.9)$ \\
$0-3$ & 17.6 & 29.8 \\
& $(9.9)$ & $(28.7)$ \\
\hline
\end{tabular}

Note: Significant parameter estimates at the $10 \%$ level (for a two-sided test) in bold. Standard deviations in parentheses. 